\title{
OS PARÂMETROS INTERNACIONAIS DE PREVENÇÃO DA VIOLÊNCIA DOMÉSTICA CONTRA MULHERES: UMA COMPARAÇÃO COM OS INSTRUMENTOS PREVISTOS NA LEI MARIA DA PENHA
}

\section{THE INTERNATIONAL STANDARDS TO PREVENT DOMESTIC VIOLENCE AGAINST WOMEN: A COMPARISON WITH THE TOOLS PROVIDED BY THE MARIA DA PENHA LAW}

\author{
${ }^{1}$ Marcia Nina Bernardes \\ ${ }^{2}$ Rodrigo de Souza Costa
}

\section{RESUMO}

Inicialmente o presente trabalho pretende-se sistematizar as definições de violência contra mulher no âmbito internacional e as definições das vítimas da violência doméstica como violação de direito internacional. Posteriormente, foca-se na construção realizada no Direito Internacional dos Direitos Humanos sobre a obrigação estatal de prevenir, especificamente, a violência doméstica e familiar contra a mulher. Em seguida pretende-se investigar os parâmetros internacionais em torno daquilo que chamamos de prevenção estrita, em que se verifica se o Estado, ao tomar ciência de possibilidade de violações concretas e específicas, toma atitudes necessárias para impedi-las de acontecer. Posteriormente, busca-se comparar esses parâmetros internacionalmente estabelecidos com aqueles adotados pela Lei n. ${ }^{\circ} 11.340$ /06, conhecida como Lei Maria da Penha, a lei brasileira de combate à violência doméstica e familiar contra a mulher.

Palavras-chave: Violência doméstica, Violência de gênero, Direitos humanos

\begin{abstract}
This paper aims, initially, to systematize the definitions of violence against women as well as the definitions of victims of domestic violence as a violation of international law. Secondly, it focuses on the standards developed at the International level related to the state obligation to prevent, specifically, domestic violence against women. Specifically, it intends to investigate the international parameters around what we call strict prevention obligations, where the state, once aware of possible concrete violations, takes necessary action to prevent them from happening. Last, we compare these international parameters with those established by Law No. 11.340/06, known as Maria da Penha Act, Brazilian law to combat domestic violence against women
\end{abstract}

Keywords: Domestic violence, Gender violence, Human rights

\footnotetext{
${ }^{1}$ Doutora em Juridical Science Doctor pela New York University - NYU, Estados Unidos. Professor Assistente pela Pontifícia Universidade Católica do Rio de Janeiro - PUC, Rio de Janeiro (Brasil). E-mail: marcianb@puc-rio.br

${ }^{2}$ Doutor em Direito pela Universidade do Estado do Rio de Janeiro - UERJ, Rio de Janeiro (Brasil). Professor de Direito pela Universidade Federal Fluminense - UFF, Rio de Janeiro (Brasil). E-mail: rodrigo.s.costa02@gmail.com
} 


\section{Introdução}

A Lei Maria da Penha (lei 11340/06) recebeu esse nome em homenagem à cearense que sobreviveu a duas tentativas de assassinato, por parte de seu então marido, que a deixaram paraplégica. Depois de 15 anos sem o transito em julgado da sentença condenatória do agressor, apesar das robustas provas constantes do inquérito, seu caso foi enviado à Comissão Interamericana de Direitos Humanos, que, em 2001, recomendou ao Brasil, dentre outras ações, a reforma de seu sistema legal de modo a permitir ações judiciais mais céleres e eficazes no combate a este tipo de agressão. Esse foi o contexto que facilitou a elaboração e a promulgação da nossa lei para coibir a violência doméstica e familiar contra a mulher. Este caso é paradigmático também por ter sido o primeiro em que se aplicou a Convenção Interamericana Para Prevenir, Punir e Erradicar a Violência contra a Mulher (Convenção Belém do Pará, ou CVM) ${ }^{1}$, que deixa clara a responsabilidade estatal por todos os tipos de violência contra a mulher, incluindo a doméstica.

No entanto, a obrigação internacional de coibir a violência doméstica pode ser controvertida para os muitos países do globo, pois não existe nenhuma convenção internacional no âmbito da ONU falando sobre o assunto, apesar de haver abundante soft law sobre o tema. Bonita Meyersfeld defende a tese de que haveria um direito costumeiro geral emergente estabelecendo essa responsabilidade de forma vinculante e cuja opinio juris seria evidenciada justamente por esse conjunto de declarações, resoluções e relatórios sobre o tema, produzidos por diferentes órgãos internacionais(MEYERSFELD, 2010).

A controvérsia torna-se ainda mais extensa devido ao fato de a violência doméstica ser um tipo de violência contra a mulher que é por definição cometida por particular, e não pelo Estado. Com efeito, a partir da CVM (art. 2) e a Declaração da ONU sobre a Eliminação da Violência Contra a Mulher (art. 2), podemos discernir três tipos de violência contra a mulher: a perpetrada pelo Estado, a perpetrada por membro da comunidade e a violência doméstica, em que o agressor e vítima estão em relação de intimidade. Por outro lado, sabemos que no Direito Internacional o Estado é o único sujeito de direito que pode ser responsabilizado por violação de direitos humanos $^{2}$. Em que medida, então, Estados podem ser responsáveis 1 Adotada pela Assembleia Geral da Organização dos Estados Americanos (OEA) no dia 09 de junho de 1994. Para ver o texto completo, http://www.cidh.oas.org/basicos/portugues/m.Belem.do.Para.htm 2 Há quem defenda como exceção as hipóteses de crimes contra a humanidade, em que indivíduos podem ser levados ao Tribunal Penal Internacional, mas aqui se defende a autonomia científica do 
internacionalmente por violações de Direitos Humanos geradas a partir de crimes decorrentes de violência doméstica?

No âmbito do sistema Interamericano de Direitos Humanos essa possiblidade deriva diretamente das obrigações constantes do artigo 7 da CVM e indiretamente da aplicação do artigo 1.1 da Convenção Americana de Direitos Humanos (CADH), anterior à CVM. O artigo 1.1 da CADH estabelece a "obrigação geral de garantia", segundo a qual, Estados devem não apenas respeitar direitos humanos e abster-se de violá-los diretamente, como também garantir que todos possam livremente usufruir desses direitos. Em diferentes casos, a Corte Interamericana de Direitos Humanos entendeu que esta obrigação geral ensejava as obrigações estatais de "prevenir, investigar e punir" e de "devida diligencia". O artigo 7, alínea e b, da CVM repete exatamente essas duas obrigações - a de garantir direitos humanos e a de devida diligência - e especifica outras nos demais incisos.

O presente artigo pretende inventariar o Direito Internacional para sistematizar os parâmetros internacionais construídos acerca da violência contra as mulheres, em especial acerca da obrigação de "prevenir" no contexto da violência contra a mulher, em geral, e de violência doméstica, em especial. Com efeito, com relação aos países que ratificaram a CVM esta obrigação inequivocamente existe, mas os seus contornos em situações concretas podem ser nebulosos. Diversos documentos internacionais que não vinculam formalmente podem funcionar como fonte interpretativa importante das obrigações formais de direito internacional. Pretende-se aqui contribuir para identificar os "consensos" com relação ao alcance destas normas (ainda que estes consensos sejam provisórios e revisitados) permitindo uma avaliação da medida em que o Brasil estaria em conformidade com as obrigações internacionais que assumiu.

Em todas as seções deste artigo, buscamos destacar, de acordo com a teoria das fontes de direito internacional, quais são as obrigações formalmente vinculantes para os Estados - aquelas que emanam de convenções internacionais ou de decisões de órgãos internacionais jurisdicionais, tais como as Cortes Interamericana e Europeia de Direitos Humanos - e quais são soft law, e, como tal, não vinculantes. Dentre as fontes não vinculantes, encontram-se as recomendações de comitês e comissões internacionais, como o Comitê CEDAW da ONU e a Comissão Interamericana de Direitos Humanos, as recomendações de relatores especiais da ONU e da OEA, as Direito Penal Internacional, como o faz Kai Ambos (AMBOS: 2008) 
resoluções das Assembleias Gerais da ONU e da OEA e as Declarações assinadas por Estados.

No entanto, um argumento que perpassa toda a estrutura deste artigo é o de que, ainda que através de soft law, já se produziu internacionalmente um conjunto sólido de entendimentos acerca do que é necessário para prevenir, investigar e punir a violência doméstica contra a mulher. Esses entendimentos são persuasivos e se infiltram nas obrigações formais de diferentes maneiras: seja através do seu reconhecimento pelos órgãos autorizados internacionalmente, seja por pressão de atores da sociedade civil para sua incorporação nas práticas estatais. De fato, talvez o aspecto mais importante da análise desses parâmetros seja a possibilidade de usá-los como critério de avaliação da conduta interna dos Estados.

O foco deste inventário, portanto, será o sistema universal e o sistema interamericano de proteção aos direitos humanos, aos quais o Brasil se submete. Eventuais referências à Corte Europeia de Direitos Humanos (Corte EDH) e à recente Convenção de Istambul (2014) ${ }^{3}$ se justificam na medida em que repetidas vezes os órgãos dos variados sistemas citam-se reciprocamente.

Desta forma, na parte 1 deste artigo, pretende-se sistematizar as definições de violência contra mulher no âmbito internacional e as definições das vítimas da violência doméstica como violação de direito internacional. Na segunda parte, foca- se na construção realizada no Direito Internacional dos Direitos Humanos sobre a obrigação estatal de prevenir, especificamente, a violência doméstica e familiar contra a mulher. Na parte 3 pretende-se investigar os parâmetros internacionais em torno daquilo que se entende como prevenção estrita, em que se verifica se o Estado, ao tomar ciência de possibilidade de violações concretas e específicas, toma atitudes necessárias para impedi-las de acontecer. Por fim, na quarta e última parte, busca-se comparar esses parâmetros internacionalmente estabelecidos com aqueles adotados pela Lei n. ${ }^{\text {o }}$ 11.340/06, conhecida como Lei Maria da Penha, a lei brasileira de combate à violência doméstica e familiar contra a mulher.

3 Convenção do Conselho da Europa para a Prevenção e Combate à Violência contra as Mulheres e à Violência Doméstica (2014). 


\section{Dadefinicãointernacionaldeviolênciadoméstica}

Bonita Meyersfeld lembra que as violações de Direitos Humanos que ensejam a responsabilização do Estado devem ser sérias e sistêmicas (MEYERSFELD, 2009, p. 685). Não é qualquer violação de direitos que será objeto de consideração do Direito Internacional. De acordo com a autora, há cinco elementos fundamentais que devem ser verificados para o reconhecimento da responsabilidade do Estado por violência doméstica: seriedade do dano, continuidade do dano, intimidade, vulnerabilidade do grupo afetado e fracasso do Estado na prevenção e repressão ao crime. Com efeito, sabe-se que violência doméstica pode ser equiparada à tortura em termos de intensidade do sofrimento físico, psicológico e moral imposto à vítima ${ }^{4}$. Mesmo formas mais amenas de agressão, no contexto de violência doméstica e de subordinação da mulher, adquirem uma seriedade que não teriam em outro contexto, pois "atos de violência, que não são severos por eles mesmos, podem se tornar severos e debilitantes se eles induzem um contínuo ambiente de medo e controle do qual a vítima é incapaz de escapar” (MEYERSFELD, 2010, p.118).

Da mesma forma, a intimidade com o agressor, que em geral é seu pai, marido, companheiro ou namorado, torna mais difícil para a vítima a compreensão de que ela está em uma relação abusiva e, por conseguinte, reunir a coragem para sair dela, encarando todas as consequências pessoais e econômicas desta decisão. Meyersfeld afirma que o elemento da intimidade complica tanto o entendimento das vítimas acerca da violência que sofrem e sua habilidade para escapar dela, quanto a reação da sociedade a esta experiência (MEYERSFELD, 2010, p.112). Não raro, estas vítimas são economicamente dependentes do agressor e sentem-se pressionadas a continuar na relação abusiva pela família ampliada (pais, sogros, cunhados e etc), por seus filhos ou mesmo por suas próprias referências acerca do seu papel social como mulher.

A vítima deste tipo de violência torna-se comumente incapaz de procurar assistência jurídica e médica devido ao seu isolamento ou à sua vulnerabilidade. Em alguns casos, por causa dos estereótipos de gênero, ela é levada a acreditar que ela deve ser responsável pela violência que suporta, e que o agressor que está correto em

4 Ver Tribunal Internacional Penal para Ex-Iugoslávia (ICTY), Câmara de Apelação, Prosecutor v Kunarac et. al, 12 de junho de 2002, paras. 151-152. Corte Interamericana de Direitos Humanos Caso González et. al. vs. México (Caso do Campo Algodoeiro). Julgamento 16 de Novembro de 2009 (Exceções Preliminares, Méritos e Reparação). Opinião Concorrente da Juiza Cecilia Medina Quiroga, paras.1, 8-9. Ver também (MACKINNON, 1993, p. 22). Ver Anistia Internacional \& Redress, Gender and Torture: Conference Report, Disponível em 〈http://www.redress.org/downloads/publications/GenderandTortureConferenceReport-191011.pdf $>$ 
exercer seu poder sobre ela. Em outros, ela sente vergonha de sua própria situação e não procura ajuda. Muitas vezes, ela não sabe para onde ir, outras não pode denunciar o abuso por causa do controle sobre suas atividades diárias pelo próprio agressor, ou, ainda, não denuncia porque não confia nas instituições existentes, e tem medo da violência subsequente, caso o agressor retorne para casa mesmo após a denúncia.

Em vista disso, essas mulheres, quando conseguem chegar à esfera pública para buscar ajuda, precisam de uma resposta condizente do Estado. O fenômeno da dupla vitimização, ou vitimização secundária, refere-se justamente às frequentes situações em que mulheres são discriminadas, agora por agentes do poder público, novamente com base em estereótipos de gênero. Uma das causas do caráter sistemático da violência doméstica consiste na omissão do Estado, que deixa de providenciar locais adequados para receber esse tipo de vítima, bem como pessoal com o treinamento necessário para lidar com este tipo de problema ${ }^{5}$. Questões como: “o que você fez para deixá-lo com tanta raiva?" ou "o que você estava fazendo fora de casa àquela hora?" podem ser terrivelmente intimidadoras, responsabilizando a própria vítima pela violência que sofre ${ }^{6}$.

No âmbito da ONU, mencionamos três documentos pertinentes para a discussão ora travada: a Convenção para Eliminação de todas as Formas de Discriminação contra a Mulher (CEDAW), de 1979, a Recomendação 19 do Comitê CEDAW e a Declaração Universal sobre a Eliminação da Violência Contra a Mulher (1993). A CEDAW, no entanto, não traz nenhuma referência explícita sobre violência contra mulher, e a luta contra esta forma de violência acaba dependendo principalmente da Recomendação Geral 19 do Comitê para a Eliminação da Discriminação contra a Mulher (Comitê) e da Declaração da ONU sobre a Eliminação da Violência Contra a Mulher, documentos destituídos de força formalmente vinculante.

Com relação aos Estados que ratificaram a CEDAW, as recomendações do Comitê criado para monitoramento da implantação da CEDAW funcionam como fontes autorizadas de interpretação da convenção e, ainda que meras recomendações e

5 A falência estatal no lidar da questão não precisa ser intencional. Ver Corte Europeia de Direitos Humanos Opuz v. Turkey (9 de Junho 2009, §111). Ver também Corte Interamericana de Direitos Humanos, Gonzalez et al v. Mexico (Caso do Campo Algodoeiro), Exceção Preliminar, Fundo, Reparações e Custos. Sentença de 16 de novembro de 2009. Serie C No. 205, §395-396.

6 Nos fatos do caso Campo Algodoeiro, pode-se encontrar diversos exemplos da dupla vitimização, ou vitimização secundária. Cf. Corte Interamericana de Direitos Humanos, Gonzales et al v. México (Caso Campo Algodoeiro) parágrafos 1-154; 196-208. 
não sentenças judiciais, informam as obrigações internacionais e determinam responsabilidades internacionais. Na Recomendação Geral n.19, de 1992², o Comitê interpreta o artigo 1 da convenção, definindo violência contra a mulher como "violência baseada no sexo, isto é, violência dirigida contra a mulher porque é mulher ou que a afeta de modo desproporcional" (parágrafo 6).

O Comitê afirma alguns parâmetros fundamentais como os seguintes: (i) violência (doméstica) contra mulher é uma forma de discriminação contra a mulher que contribui para a sua vulnerabilidade e isolamento; (ii) a violência contra a mulher envolve atos, ou ameaças de atos, que infligem sofrimentos físicos, mentais ou sexuais; (iii) esta forma de violência não se limita a atos praticados por agentes públicos, e o Estado deve agir com a devida diligência para impedir, investigar e punir a violação cometida por particulares; (iv) a violação não precisa ser intencional, ou seja, politicas públicas aparentemente neutras, mas que afetem as mulheres de maneira desproporcional, também caracterizam violência contra mulher. $\mathrm{O}$ quarto parâmetro parece especialmente relevante, pois deixa inequívoca a obrigação dos Estados de assegurarem a igualdade material, e não apenas formal, entre homens e mulheres.

Dois princípios norteadores da discussão sobre violência doméstica foram estabelecidos pelo comitê: o primeiro, que afirma a circularidade entre discriminação contra mulher e violência, e o segundo, relativo à crítica à separação clássica entre os âmbitos público e privado. Na medida em que o Estado supostamente não deve interferir em assuntos privados e que a mulher resta tradicionalmente identificada com a vida privada, ela fica invisibilizada e excluída do âmbito de proteção estatal, podendo, inclusive, sofrer violência doméstica sem que isso seja entendido como assunto de interesse público.

A Declaração da ONU sobre a Eliminação da Violência Contra a Mulher (1993), por sua vez, foi elaborada durante a Convenção de Viena sobre Direitos Humanos e aprovada pela Assembleia Geral da ONU no mesmo ano ${ }^{8}$. Como

7Cf. Comitê para Eliminação da Discriminação contra a Mulher, $11^{\text {th }}$ sessão, 1992

8Cfr. Assembleia Geral da ONU, A/RES/48/104, 23 de fevereiro de 1994, pag. 3. A Declaração sobre a Eliminação da Violência contra a Mulher de 20 de dezembro de 1993 foi aprovada pela Assembleia Geral das Nações Unidas na sua Resolução 48/104 de 23 de fevereiro de 1994, Para acessar o texto completo, $\quad$ http://daccess-dds-ny.un.org/doc/UNDOC/GEN/N94/095/08/PDF/N9409508.pdf? OpenElement Além do projeto de declaração constavam do documento que emergiu desta conferencia, a "Declaração e Plano de Ação de Viena", a recomendação que a ONU adotasse um protocolo que permitisse ao Comitê CEDAW o recebimento de comunicações individuais de violações de diretos das mulheres. 
Declaração, na técnica normativa internacional, limita-se a enunciar aspirações dos Estados signatários e não vincula comportamentos, Mas, na medida em que foi votada por Estados, pode ser considerada prova da existência de opinio juris de direito costumeiro recém-consolidado ou em consolidação. Esta Declaração, no artigo 2, reitera a definição dada pelo Comitê e sistematiza os tipos de violência contra mulher: (i) violência familiar ou doméstica; (ii) por outros membros da comunidade; e (iii) perpetrada ou tolerada pelos agentes de Estado.

A extinta Comissão de Direitos Humanos reafirmou esses entendimentos na Resolução 2003/45. ${ }^{9}$ Esta resolução tampouco tem a força obrigatória de uma convenção internacional, mas, assim como a declaração acima mencionada, foi votada por representantes de Estados e não por especialistas e, portanto, tem peso significativo no direito internacional.

No âmbito do Sistema Interamericano de Direitos Humanos, a obrigação estatal de prevenir, erradicar e punir qualquer forma de violência contra a mulher é clara para os estados-partes da Convenção Belém do Pará, de 1994. A CVM, em grande medida, reitera os termos dos documentos da ONU relativos à definição de violência contra a mulher e os tipos de violência que existem, incluindo a doméstica. No entanto, como Convenção e não mera soft law, aplica-se de forma obrigatória com relação aos países que a ratificaram.

Sobre o perfil da vítima a ser protegida, em todos esses documentos, as obrigações dos Estados relativas à coibição da violência doméstica se colocam em relação às vítimas mulheres. Não há, no direito internacional, ao contrário do que se passou no Brasil até a decisão das ADI $4424^{10}$ e ADC 19 pelo Supremo Tribunal Federal Brasileiro, nenhuma controvérsia quanto à necessidade de proteção especial

9 Resolução 2003/45 da Comissão de Direitos Humanos, aprovada em 23 de abril de 2003 decidiu a renovação do mandato da Relatora Especial sobre a violência contra a mulher. A Relatoria Especial sobre a Violência contra a Mulher foi criada pela Comissão de Direitos Humanos da ONU por meio da sua Resolução 1994/45 aprovada em 4 de março de 1994. Atualmente, a responsável é a sul-africana, Sra. Rashida Manjoo. Vejamos: "4.Afirma que por "violencia contra la mujer" se entiende todo acto de violencia que tenga o pueda tener como resultado un daño o sufrimiento físico, sexual o psicológico para la mujer, así como las amenazas de tales actos, la coacción o la privación arbitraria de la libertad, tanto si se producen en la vida pública como en la vida privada, e incluida la violencia doméstica, los delitos cometidos por cuestiones de honor, los crímenes pasionales, la trata de mujeres y niñas, las prácticas tradicionales nocivas para la mujer, incluida la mutilación genital femenina, el matrimonio precoz y forzado, el infanticidio de niñas, los actos de violencia y los asesinatos relacionados con la dote, los ataques con ácido y la violencia relacionada con la explotación sexual comercial y con la explotación económica;".

10 A decisão pode ser encontrada em

http://www.stf.jus.br/portal/jurisprudencia/listarJurisprudencia.asp?s1=\%28ADI

$\% 29 \% 284424 \% 2 \mathrm{ENUME} \% 2 \mathrm{E}+\mathrm{OU}+4424 \% 2 \mathrm{EACMS} \% 2 \mathrm{E}$

\%29\&base=baseAcordaos\&url=http://tinyurl.com/m7pdm6b 
às mulheres. O Mecanismo de Seguimento da Convenção de Belém do Pará (MESECVI0, órgão encarregado de monitorar a implementação da CVM chega a mencionar no seu Segundo Relatório Hemisférico,

"También mostró su preocupación por las normas genéricamente neutras adoptadas en el marco de la lucha contra la violencia familiar. Con ello se invisibilizaba el hecho que mujeres, niñas y adolescentes constituían el mayor número de víctimas de violencia, y que responde a una situación de desigualdad histórica entre hombres y mujeres que legitima la violación de sus derechos". (p. $17)^{11}$

Quando se pergunta quais mulheres poderão ser protegidas, o art. 5 da CVM afirma que

"Toda mulher poderá exercer livre e plenamente seus direitos civis, políticos, econômicos, sociais e culturais e contará com a total proteção desses direitos consagrados nos instrumentos regionais e internacionais sobre direitos humanos. Os Estados Partes reconhecem que a violência contra a mulher impede e anula o exercício desses direitos."

No artigo 9, a CVM lista condições que tornam certas mulheres especialmente vulneráveis à violência, tais como as pertencentes a minorias étnicas e raciais, as migrantes, deslocadas, e refugiadas, as gestantes, portadoras de deficiência, as pobres, as que estão sob custódia do estado e as que estão em um contex to de conflito $\operatorname{armado}^{12}$.

\section{II.Sobreaobrigaçãodeprevenir:}

No âmbito da ONU, o Comitê CEDAW afirmou por diversas vezes, tanto na Recomendação Geral no. 19 (art.9), quanto em comunicações individuais que analisou $^{13,}$ que o Estado pode ser responsabilizado por atos de particulares, caso não aja com a devida diligência para prevenir, investigar e punir atos de violência.

No âmbito do sistema interamericano, esta obrigação vem estabelecida com maior clareza. O art.7 da CVM, que estabelece as obrigações que os Estados assumem ao ratificarem ou aderirem ao instrumento, afirma nas alíneas "a" e "b", respectivamente, que os Estados devem abster-se de praticar qualquer ato de violência contra a mulher e que devem agir com o devido zelo para prevenir, investigar e punir a violência contra a mulher cometida por particulares. Nos demais incisos, afirma uma

11 Disponível em http://www.oas.org/es/cidh/mujeres/default.asp Acesso em 16/08/2015.

12 Diferente do que faz a legislação brasileira, o art. 9, no entanto, silencia sobre um aspecto importante de agravamento da vulnerabilidade à violência que é a orientação sexual da vítima. 13 Ver, por exemplo, as comunicações individuais n. 02/2003 (Ms. A.T. v. Hungria) e No. 05/2005 (Ms. Sahide Goecke v. Austria). 
série de outros compromissos que dão concretude à chamada "obrigação geral de garantia", prevista também no artigo 1.1 da $\mathrm{CADH}$. No que se refere à violência doméstica, que por definição é cometida por particular, é de especial interesse entender os parâmetros relativos à garantia, como veremos a seguir.

Cumpre registrar, ainda, que nos termos do art. 12 da CVM, qualquer pessoa ou grupo de pessoas ou entidade não governamental pode peticionar à Comissão Interamericana de Direitos Humanos (CIDH) para denunciar violação a estas obrigações e, ainda que o mesmo artigo não mencione explicitamente a jurisdição da Corte IDH sobre estas violações, este Tribunal, no caso Gonzales et. al. V. Mexico (caso Campo Algodoeiro) entendeu que pode examiná-las. ${ }^{14}$ Neste sentido, o caráter formalmente vinculante e justicializável das obrigações relativas ao dever de garantia dos Estadospartes da convenção resta pacificado.

As obrigações gerais de prevenir, investigar e punir foram definidas pela Corte IDH como obrigações de meio, e não de resultado. Neste sentido, para que um Estado seja eximido da responsabilidade internacional por uma violação que não preveniu, e cujo perpetrador não foi punido, é preciso que seja comprovado que o Estado agiu com a devida diligência, principalmente na investigação.

A obrigação de prevenir violações de direitos humanos pode ser entendida de duas formas: como prevenção geral, no sentido da adoção de políticas sociais, econômicas e culturais efetivas que atinjam as causas mais profundas dos padrões sistemáticos de violação, e como prevenção estrita, em que se verifica se o Estado, ao tomar ciência de possibilidade de violações concretas e específicas, toma atitudes necessárias para impedi-las de acontecer. No segundo sentido, os parâmetros de prevenção se aproximam aos parâmetros de investigação, como veremos.

Com relação à prevenção no sentido geral, existem alguns documentos que estabelecem parâmetros internacionais para dar concretude à obrigação. É certo que, mais uma vez, esses parâmetros caracterizam "soft law" na maior parte das vezes e não constituem, per se, fonte de obrigação formal para os Estados. No entanto, como já mencionado, há diversas formas através das quais as fontes de direito internacional se comunicam e se transformam. Soft law, por vezes, pode ser diretamente incorporada por algum órgão jurisdicional internacional, por outras, pode ser entendida como prova de um direito costumeiro em formação. Por isso, ainda que

14 Corte Interamericana de Direitos Humanos, Gonzalez et al v. Mexico (Caso do Campo Algodoeiro), Exceção Preliminar, Fundo, Reparações e Custos. Sentença de 16 de novembro de 2009. Serie C No. $205, \S 31-77$. 
tecnicamente de observação voluntária, estas fontes são de importante consideração para a compreensão das obrigações internacionais.

No âmbito da ONU, a mencionada Recomendação Geral 19 do Comitê CEDAW lista, no artigo 24, uma série de ações que os Estados devem executar para erradicar a cultura e as condições materiais que propiciam a discriminação e a violência contra a mulher. E ainda, o Informe de 2011 da Relatora Especial da ONU sobre "a violência contra a mulher, suas causas e consequências"15 reitera o entendimento da Recomendação 19 sobre o papel da discriminação baseada em gênero na reprodução do fenômeno da violência contra a mulher. Reconhece que se avançou bastante nos últimos 30 anos na garantia da não-discriminação às mulheres no plano jurídico-formal, mas alerta que ainda é necessário trabalhar-se mais para que essa equidade seja realidade fática. Neste sentido, a relatora dá ênfase às campanhas educacionais e midiáticas contra a violência contra a mulher e contra os estereótipos de gênero, reivindica o estabelecimento de dias nacionais contra a violência contra a mulher, e estimula a criação de cursos de capacitação e de sensibilização constantes para diferentes agentes estatais: policia, ministério público, magistrados, assistentes sociais, enfermeiros e médicos, dentre outros. $\mathrm{O}$ informe ainda, fala do efeito preventivo e simbólico que leis especiais contra a violência contra mulher podem surtir.

Na Declaração e Plataforma de ação da IV Conferência Mundial sobre a Mulher, ocorrida em Beijing em 1995, além de estabelecer que os Estados-Parte estão determinados a "Prevenir e eliminar todas as formas de violência contra as mulheres e meninas", ainda lista dentro do objetivo estratégico D.1. 34 medidas que devem ser adotadas de forma integrada para prevenir e eliminar a violência contra a mulher ${ }^{16}$

No âmbito da OEA, e ainda sobre a prevenção geral, a Comissão Interamericana das Mulheres recomendou à Assembleia Geral da OEA a promulgação de uma declaração sobre como "Fortalecer los esforços de prevención de la violencia contra las mujeres"17, aprovada em 2014 com o nome de "Declaração de Pachuca." Este documento, assinado por Estados, ainda que não tenha o condão de gerar obrigações internacionais no sentido formal, tem um peso maior como soft law do que

15 Cfr. Assembleia Geral da ONU, A/66/215, de 1 de agosto de 2011, paragrafo 56. Veja-se E/CN.4/2006/61, pars. 44 e 45.

16 A lista com essas medidas pode ser achada em http://www.unfpa.org.br/Arquivos/declaracao_beijing.pdf

17 Cfr. OEA/Ser.L/II.5.32, CIM/CD/doc.16/14 rev.3, de 27 de maio de 2014 
os informes de relatores especiais. Além das campanhas midiáticas e educacionais (par. 16), esta declaração enfatiza a importância da compilação de dados sobre os fatores que aumentam o risco de violência contra a mulher (para. 9), destaca a necessidade de participação popular na formulação e avaliação de politicas públicas (paragrafos 5 e 10), bem como a importância de "um enfoque transversal de diversidade para responder às necessidades de grupos específicos" (par. 7) e "marginalizados"(par. 10).

Especificamente com relação à violência doméstica, a CIDH, por sua vez, no Caso Maria da Penha (Informe 54/2001) estabeleceu uma série de recomendações ao Estado Brasileiro, com vistas a evitar ou diminuir o caráter sistemático da violência doméstica em nosso país. Dentre elas:

4. Prosseguir e intensificar o processo de reforma que evite a tolerância estatal e o tratamento discriminatório com respeito à violência doméstica contra mulheres no Brasil. A Comissão recomenda particularmente o seguinte: a) Medidas de capacitação e sensibilização dos funcionários judiciais e policiais especializados para que compreendam a importância de não tolerar a violência doméstica; b) Simplificar os procedimentos judiciais penais a fim de que possa ser reduzido o tempo processual, sem afetar os direitos e garantias de devido processo; c) $\mathrm{O}$ estabelecimento de formas alternativas às judiciais, rápidas e efetivas de solução de conflitos intrafamiliares, bem como de sensibilização com respeito à sua gravidade e às conseqüências penais que gera; d) Multiplicar o número de delegacias policiais especiais para a defesa dos direitos da mulher e dotá-las dos recursos especiais necessários à efetiva tramitação e investigação de todas as denúncias de violência doméstica, bem como prestar apoio ao Ministério Público na preparação de seus informes judiciais. e) Incluir em seus planos pedagógicos unidades curriculares destinadas à compreensão da importância do respeito à mulher e a seus direitos reconhecidos na Convenção de Belém do Pará, bem como ao manejo dos conflitos intrafamiliares. ${ }^{18}$

\section{III.PrevencãoEstrita:}

As obrigações relativas à prevenção em sentido estrito dizem respeito à conduta do Estado no sentido de prevenir casos concretos de violência contra a mulher. Dizem respeito, portanto, à qualidade do acesso de vítimas e familiares de vítimas aos mecanismos de proteção e também dizem respeito aos protocolos de investigação efetivamente colocados em prática pelo Estado. O descumprimento

18 O relatório pode ser encontrado em http://www.sbdp.org.br/arquivos/material/299_Relat\%20n.pdf Acesso em 15/08/2015. 
destas obrigações têm um efeito imediato na ocorrência do fenômeno da dupla vitimização das mulheres e na reprodução do ciclo da violência contra mulher.

A Corte EDH, no que se refere à prevenção em sentido estrito, produziu duas decisões muito elucidativas, citadas pela Corte IDH no mencionado Caso Campo Algodoeiro. No primeiro caso, Osman v. Reino Unido (1999), a Corte Europeia estabeleceu um teste, com duas partes, para saber se o Estado tinha responsabilidade internacional por ato de violência doméstica. A primeira parte do teste refere-se à identificação do "elemento do conhecimento:" as autoridades estatais sabiam, ou deveriam saber, do risco imediato de atos criminais a serem perpetrados por um indivíduo? A segunda parte do teste refere-se à identificação do elemento da devida diligência: tendo ciência do risco, as autoridades tomaram todas as medidas dentro de suas competências que, em um juízo razoável, poderiam ter tido o efeito de evitar o risco $?^{19}$ Esse teste foi confirmado no caso Opuz v. Turquia (2009), onde se interpretou a obrigação de devida diligência de modo mais amplo e robusto do que no caso anterior e onde foram alguns critérios para averiguar o seu cumprimento. ${ }^{20}$

No âmbito da ONU, o Informe de 2006 da Relatora Especial da ONU sobre a violência contra a mulher, suas causas e consequências ${ }^{21}$, tanto a polícia, quanto os membros do Judiciário, têm um papel importante na prevenção a este tipo de crime.

Segundo o informe, a Polícia deve responder a toda e qualquer solicitação de assistência e de proteção em casos de presumida violência doméstica. Comunicações de abusos por parte de familiares e de pessoas próximas não podem ser consideradas menos graves e, ainda, a policia deve prontamente se deslocar ao lugar dos fatos todas as vezes em que o denunciante, seja ele quem for, informar que a violação é iminente ou está em curso, ou quando o denunciante informar ter havido violência doméstica anteriormente. Assim que receber a comunicação, a polícia: ${ }^{22}$

a) entrevistará a las partes y a los testigos, incluidos los niños, en salas separadas para que tengan la oportunidad de hablar libremente;

19 Osman v. Reino Unido (1999) 29E.H.R.R.245 ECtHR, parágrafo 115. Ver também MEYERSFELD, Bonita. "Opuz v. Turkey: Confirming the State Obligation to Combat Domestic Violence. In European Human Rights Law Review. No.5, 2009, p. 684.

20 Opus v. United Kingdom (App. No.33401/02). Ver também MEYERSFELD, Bonita. “Opuz v. Turkey: Confirming the State Obligation to Combat Domestic Violence. In European Human Rights Law Review. No.5, 2009, p. 686.

21 Informe apresentado pela Relatora Especial sobre a violência contra a mulher, com inclusão de suas causas e consequências, Sra. Radhika Coomaraswamy, em conformidade com a resolução 1995/85 da Comissão de Direitos Humanos Marco da legislação modelo sobre a violência doméstica. E/CN.4/1996/53/Add.2, 2 de fevereiro de 1996.

22 Págs. 5, 6, 7 
b) tomará nota de la denuncia detalladamente;

c) informará a la víctima de sus derechos, esbozados infra;

d) rellenará y presentará un atestado de violencia doméstica, conforme a lo exigido por la ley;

e) trasladará a la víctima, o dispondrá su traslado, al hospital o al servicio médico más cercano para su tratamiento, de ser necesario; f) trasladará a la víctima y a los hijos o personas a cargo de la víctima, o dispondrá su traslado, a un lugar seguro, de ser necesario; g) protegerá a la persona que denunció la violencia;

h) verá que el agresor desaloje el hogar o, de no ser posible, y si la víctima sigue en peligro, detendrá al agresor."

Além disso, como forma de permitir o mais amplo acesso à rede dos sistemas de Justiça existe a previsão de que: “19. La víctima podrá presentar una denuncia de violencia doméstica ante un servicio de salud estatal o privado, que la transmitirá a la policía de la división judicial en que se encuentra ese servicio de salud." ${ }^{23}$ :

Com relação à atuação do Judiciário, é de se ressaltar que existe a previsão de que este deverá editar medidas de urgência e que deve-se realizar a audiência em 10 dias, contados a partir da data da solicitação da proteção.

Tais medidas, previstas no mesmo informe, podem ser as mais variadas, tais $\operatorname{como}^{24}$ :

“29. En virtud de la orden provisional de restricción se podrá:

i) obligar al agresor a desalojar la vivienda familiar;

ii) reglamentar el acceso del agresor a los hijos a cargo;

iii) restringir el contacto del agresor con la víctima en su lugar de trabajo u otros lugares frecuentados por la víctima;

iv) obligar al agresor a pagar las facturas médicas de la víctima;

v) restringir los actos de disposición unilateral de los bienes comunes;

vi) informar a la víctima y al agresor que si el agresor infringe la orden de restricción, podrá ser detenido y procesado;

vii) informar a la víctima que, no obstante la existencia de una orden de restricción dictada en virtud de la legislación sobre la violencia doméstica, ésta podrá solicitar del fiscal que ejercite la acción penal contra el agresor;

viii) informar a la víctima que, no obstante la existencia de una orden de restricción en virtud de la legislación sobre la violencia doméstica y del ejercicio de una acción penal, también podrá iniciar un proceso civil y demandar el divorcio, la separación y una indemnización por daños y perjuicios;

ix) exigir a cada parte que cumpla con el deber permanente de declarar ante los tribunales en todo procedimiento de solicitud de una orden de protección en cualquier litigio civil, en un procedimiento ante tribunales de menores o en un procedimiento penal que impliquen a una u otra parte."

23 Pág. 6

24 Págs. 9, 10, e 11 
Desta forma, acredita-se que se tenha conseguido estabelecer os parâmetros gerais coletados no Direito Internacional dos Direitos Humanos referentes à obrigação de prevenir a violência doméstica e familiar contra a mulher. Desta forma, o necessário e seguinte passo é investigar se a lei brasileira contra a violência doméstica e familiar contra a mulher, Lei n. ${ }^{\circ}$ 11.340/06, aproxima-se ou não desses padrões agora definidos.

\section{IV.Ocasobrasileiro:}

\section{a) Definição de violência doméstica:}

Como é sabido, a Lei n. ${ }^{\circ} 11.340$ estabeleceu seu âmbito de atuação como sendo o da violência doméstica e familiar baseada no gênero.

Para tanto, estabeleceu o legislador dois artigos fundamentais que delimitam o âmbito de incidência da lei: o artigo $5^{\circ}$, que traz o conceito de violência doméstica e familiar e o artigo $7^{\circ}$ que explicita as formas de violência contra a mulher.

Ressalte-se que o artigo $5^{\circ}$ da Lei 11.340/2006, tem seu sentido reduzido da definição utilizada pela Convenção Interamericana para Prevenir, Punir e Erradicar a Violência Contra a Mulher (CEDAW), também conhecida como Convenção de Belém do Pará, que aduz que, para ser configurada, deve haver uma ação ou omissão que cause a qualquer mulher danos em diferentes graus, numa relação doméstica de intimidade ou de afetividade, sendo certo que a violência deve ter se operado em razão do gênero.

\section{a1. Formas de violência contra a mulher}

A violência contra as mulheres é expressão extrema da discriminação de gênero, que se encontra no espaço doméstico e se projeta para o espaço público. É componente fundamental no sistema de dominação, sendo uma maneira que o agressor encontra de perpetuar o papel de subordinação atribuído à mulher.

Quanto ao conceito de violência, o artigo $5^{\circ}$ deve ser compreendido conjuntamente com o artigo $7^{\circ}$ da Lei 11.340/2006, que institui um rol não taxativo de modalidades de violência passíveis de serem perpetradas contra a mulher a fim de facilitar, didaticamente, a sua aplicação. Com isto, o catálogo de situações fica em 
aberto, podendo haver outras modalidades de violência que não as elencadas no artigo $7^{\circ}$, desde que presentes os requisitos dos artigos $5^{\circ}$ - que haja motivação de gênero e que se dê no âmbito da família, da unidade doméstica ou no seio das relações íntimas de afeto. Esta violência é reconhecida pela lei, em seu artigo $6^{\circ}$, como uma forma de violação de direitos humanos.

Embora seja a forma física (inciso I) a mais visível e identificável, que gera consequências materialmente comprováveis, a sua ocorrência não poucas vezes indica possibilidades de existência das demais formas de violência, tais como as exemplificadas no artigo $7^{\circ}$.

Conforme dispõe o artigo $7^{\circ}$, inciso II da Lei, a violência psicológica é aquela entendida como qualquer conduta que lhe cause dano emocional e diminuição da autoestima ou que lhe prejudique e perturbe o pleno desenvolvimento ou que vise degradar ou controlar suas ações, comportamentos, crenças e decisões, mediante ameaça, constrangimento, humilhação, manipulação, isolamento, vigilância constante, perseguição contumaz, insulto, chantagem, ridicularização, exploração $e$ limitação do direito de ir e vir ou qualquer outro meio que lhe cause prejuízo à saúde psicológica è à autodeterminação.

Nesta hipótese, verifica-se a negação do exercício da autonomia da vontade pelo agressor em face da mulher em situação de violência, o que eventualmente ocasiona uma incapacidade na reação da vítima, e a consequente anulação de sua identidade frente ao agressor.

As práticas contra a liberdade sexual e reprodutiva se consubstanciam na violência sexual, descrita no inciso III, e geram uma preocupação maior no que tange às relações entre cônjuges, companheiros, namorados, pessoas que dividem momentos de intimidade. Virgínia Feix demonstra a dificuldade de aceitação da liberdade sexual da mulher:

Como se o "sim" dito no cartório, no altar, no bar ou no motel impusesse à mulher um consentimento permanente, inquestionável, infalível, irretratável. Não. O exercício da sexualidade deve ser sempre contratado, e os contratantes, para garantia de sua dignidade, devem ser livres para destratar a qualquer tempo.(FEIX, 2011, p. 206)

A violência patrimonial consiste na violação dos direitos econômicos das mulheres, tendo respaldo no artigo $5^{\circ}$ da Convenção Belém do Pará, que determina 
que toda mulher poderá exercer livre e plenamente seus direitos econômicos, entre outros, e deverá contar com total proteção dos mesmos pelo Estado. A destruição de bens ou o impedimento de sua utilização contribuem de forma direta para a manutenção da situação de vulnerabilidade, visto que impede a liberdade e a capacidade da mulher, atentando contra sua independência. Virgínia Feix destaca que a inclusão da mulher no mercado de trabalho e independência econômica das mulheres

é um fenômeno recente, e que a retirada dos obstáculos legais, burocráticos e culturais para a livre disposição de seus bens, inclusive rendimentos, ainda está sendo conquistada. Disso decorre que, em muitas situações, os homens permanecem na condição de chefia da família, administrando os bens e monopolizando o poder econômico da comunidade familiar, o que pode ser considerado moeda de troca ou vantagem na imposição de sua vontade e manutenção de relação desigual de poder. .(FEIX, 2011, p. 208)

Por fim, no derradeiro inciso do artigo $7^{\circ}$, encontra-se a violência moral, associada à violência psicológica, e que influi diretamente na autoestima e no reconhecimento social da mulher.

\section{a2. Relações interpessoais que ensejam a aplicação da Lei}

Os incisos I, II e III do artigo $5^{\circ}$ trazem importantes definições a serem observadas pelo operador do Direito e cuja análise é indispensável no presente momento. Eles determinam critérios que, alternativamente, devem ser somados à definição de ação ou omissão baseada no gênero, para aplicação da Lei 11.340/2006.

$\mathrm{O}$ primeiro inciso define o âmbito da unidade doméstica como sendo $o$ espaço de convívio permanente de pessoas, com ou sem vínculo familiar, inclusive as esporadicamente agregadas. Quando se trata da violência em âmbito doméstico, adentra-se a uma estrutura muito sensível nas relações interpessoais. A lei não limita, desta maneira, às relações familiares, tornando maior sua abrangência e a tutela da mulher em situação de violência.

Nucci conceitua a unidade doméstica como sendo

o local onde há o convívio permanente de pessoas, em típico ambiente familiar, vale dizer, como se família fosse, embora não haja necessidade de existência de vínculo familiar, natural ou civil. (NUCCI, 2007, p. 1043) 
A violência doméstica pode ter intersecção com a violência familiar, mas atinge também indivíduos que vivam ou convivam no mesmo território, ainda que não pertencentes ao núcleo familiar. O domínio exercido territorialmente não é apenas geográfico, mas antes simbólico. As agressões praticadas contra integrantes da unidade doméstica podem ocorrer fora dela, não havendo sua descaracterização. (SAFFIOTI, 2014, p. 82-91)

O inciso II do artigo $5^{\circ}$ trata de conceituar "âmbito da família" de forma ampla, abrangendo uma variedade de laços de pertencimento, sendo este a comunidade formada por indivíduos que são ou se consideram aparentados, unidos por laços naturais, por afinidade ou por vontade expressa.

A dificuldade de se auferir o cometimento de atos de violência nas relações privadas, sobretudo nos seios domésticos e familiares, é patente, como demonstram Fabiane Simioni e Rúbia Abs da Cruz:

Nos espaços familiares, onde as relações interpessoais entre os sujeitos foram historicamente interpretadas como restritas e privadas, a complacência e a impunidade para com a violência praticada nesse âmbito encontraram sua legitimação social. Criou-se um senso comum apoiado na ideia de que o espaço doméstico é 'sagrado', acreditando-se que aquilo que ocorre entre familiares não ameaça a ordem social, ou que a forma como aqueles sujeitos se relacionam é natural, operando-se com a ficção de que a liberdade é vivida na esfera pública e a privação na esfera privada(SIMIONI \& DA CRUZ, 2011, P. 187).

Ainda, o inciso III do artigo $5^{\circ}$ contribui para uma margem maior de aplicabilidade da Lei Maria da Penha, visto que inclui dentre suas competências as relações afetivo-sexuais momentâneas, duradouras ou situacionais, não se referindo a qualquer critério para a caracterização do relacionamento. (SIMIONI \& DA CRUZ, 2011, P. 189)

Observa-se que o legislador não determinou ser necessária a convivência sob o mesmo teto do agressor e da mulher em situação de violência para a incidência da lei. A abrangência das relações faz com que o aplicador do Direito possa incluir também pessoas "esporadicamente agregadas", como a empregada doméstica, diaristas, motoristas, entre outras pessoas que façam parte do convívio contínuo, porém sem coabitação. 


\section{a3. A prática da violência baseada no gênero}

Enfim, atenta-se ao fato de que a violência doméstica e familiar contra a mulher somente é verificada se for praticada em razão do gênero. A violência em razão do gênero decorre de um arranjo social de gênero que privilegia há tempos o masculino. É a violência dirigida contra a mulher, porque é mulher, ou que a afeta de forma desproporcional. É evidente que aqui encontra-se um desafio interpretativo para o magistrado, identificar quando a violência contra a mulher é ou não baseada no gênero.

Com isto, observa-se que o conceito elaborado no artigo $5^{\circ}$ deve ser compreendido de maneira cumulativa, devendo estar presentes todos os seus elementos: que a mulher esteja em situação de violência no âmbito doméstico e/ou familiar (conforme as hipóteses elencadas nos incisos do dispositivo), e, ainda, que a violência tenha ocorrido em razão do gênero.

A gravidade que o contexto proporciona à vítima de violência em razão do gênero levou diversos Tribunais a não interpretarem a Lei de forma restrita, compreendendo como gênero o papel social exercido pelo indivíduo em situação de violência doméstica e familiar, ampliando de maneira substancial a proteção dos direitos fundamentais destes indivíduos.

A prática do método interpretativo pelo magistrado quando da aplicação da Lei ao caso concreto, compreendendo a ordem de valores como elemento de integração, deve levar em conta o dinamismo da sociedade e dos constantes processos de modificação cultural e social, mostrando-se particularmente importante em se tratando das novas estruturas familiares afirmadas nas últimas décadas. A interpretação deve ser axiológica, visando à efetividade da prestação jurisdicional justa e adaptada às modificações sociais.

Com isto, dado o contexto do surgimento da Lei 11.340/06 de busca da proteção dos direitos fundamentais de mulheres em situação discriminatória, não restam dúvidas de que seu objetivo jamais foi o de deixar ao desamparo vítimas de violência em razão do gênero, caso a violência advenha da discriminação contra a mulher. Mais que isso, observa-se que a Lei n. ${ }^{\circ} 11.340 / 06$ pode ser entendida como verdadeira ação afirmativa, editada com o claro objetivo de inicialmente minorar e, quem sabe, erradicar essa evidente situação de desigualdade e violência experimentada por um sem número de mulheres. 
Com isto, aparentemente, a proteção que propõe a Lei deve compreender o sistema de gênero de maneira ampla, visto que as desigualdades entre homens e mulheres são fruto de representações culturais, relacionadas a questões identitárias.

Nota-se a importância do parágrafo único do artigo $5^{\circ}$ da Lei 11.340/2006, que determina que as relações pessoais nas quais está envolvida a mulher em situação de violência independem da orientação sexual. Neste sentido, Carmen Hein de Campos elucida que

a Lei opera outro rompimento da identidade fixa, ao dispor que a mulher lésbica também pode ser agressora. Esse dispositivo traz duas consequências: a primeira, já apontada por Maria Berenice Dias (2010), é a ampliação do conceito de família, incluindo a união entre mulheres de mesmo sexo e, com isso, rompendo o dualismo de gênero. A segunda, no reconhecimento explícito da possibilidade de violência entre as mulheres, rompendo com a noção fixa de mulher vítima.(CAMPOS, 2011, p. 7)

Com a afirmação de que a mulher é que está sob a proteção da lei, não havendo distinção quanto à sua orientação sexual, busca a preservação plena da dignidade da pessoa humana, levando em consideração o gênero adotado pela pessoa vitimada. Assim, assegura a proteção a lésbicas, travestis, transexuais e transgêneros do sexo feminino, que mantém relação de afeto em âmbito doméstico ou familiar.

\section{a4. Sobre a obrigação de prevenir}

No sentido enunciado pelo Direito Internacional, a Lei n. ${ }^{\circ} 11.340 / 06$ traz em seu corpo uma tentativa de amarrar políticas sociais, econômicas e culturais com o escopo de erradicar os padrões sistemáticos de violência doméstica e familiar contra a mulher.

O artigo $8^{\circ}$ da Lei traz a linha mestra a partir da qual as políticas públicas visam a combater a violência doméstica e familiar contra a mulher devem ocorrer:

Art. 8o A política pública que visa coibir a violência doméstica e familiar contra a mulher far-se-á por meio de um conjunto articulado de ações da União, dos Estados, do Distrito Federal e dos Municípios e de ações não-governamentais, tendo por diretrizes:

I - a integração operacional do Poder Judiciário, do Ministério Público e da Defensoria Pública com as áreas de segurança pública, assistência social, saúde, educação, trabalho e habitação;

II - a promoção de estudos e pesquisas, estatísticas e outras informações relevantes, com a perspectiva de gênero e de raça ou etnia, concernentes às causas, às consequências e à frequência da violência doméstica e familiar contra a mulher, para a 
sistematização de dados, a serem unificados nacionalmente, e a avaliação periódica dos resultados das medidas adotadas;

III - o respeito, nos meios de comunicação social, dos valores éticos e sociais da pessoa e da família, de forma a coibir os papéis estereotipados que legitimem ou exacerbem a violência doméstica e familiar, de acordo com o estabelecido no inciso III do art. $1^{\circ}$, no inciso IV do art. $3^{\circ} \mathrm{e}$ no inciso IV do art. 221 da Constituição Federal;

IV - a implementação de atendimento policial especializado para as mulheres, em particular nas Delegacias de Atendimento à Mulher; $\mathrm{V}$ - a promoção e a realização de campanhas educativas de prevenção da violência doméstica e familiar contra a mulher, voltadas ao público escolar e à sociedade em geral, e a difusão desta Lei e dos instrumentos de proteção aos direitos humanos das mulheres;

VI - a celebração de convênios, protocolos, ajustes, termos ou outros instrumentos de promoção de parceria entre órgãos governamentais ou entre estes e entidades não-governamentais, tendo por objetivo a implementação de programas de erradicação da violência doméstica e familiar contra a mulher;

VII - a capacitação permanente das Polícias Civil e Militar, da Guarda Municipal, do Corpo de Bombeiros e dos profissionais pertencentes aos órgãos e às áreas enunciados no inciso I quanto às questões de gênero e de raça ou etnia;

VIII - a promoção de programas educacionais que disseminem valores éticos de irrestrito respeito à dignidade da pessoa humana com a perspectiva de gênero e de raça ou etnia;

IX - o destaque, nos currículos escolares de todos os níveis de ensino, para os conteúdos relativos aos direitos humanos, à equidade de gênero e de raça ou etnia e ao problema da violência doméstica e familiar contra a mulher.

Percebe-se a existência de dois padrões de políticas públicas de combate à violência doméstica e familiar contra a mulher. Inicialmente, nota-se um grupo de propostas centradas na necessária articulação entre as diversas esferas de governo e das diversas áreas do sistema de Justiça com o objetivo de combater a violência doméstica, refletida na possibilidade de a integração operacional do Poder Judiciário, do Ministério Público e da Defensoria Pública com as áreas de segurança pública, assistência social, saúde, educação, trabalho e habitação, a capacitação permanente das Polícias Civil e Militar, da Guarda Municipal, do Corpo de Bombeiros e dos profissionais pertencentes aos órgãos e às áreas enunciados no inciso I quanto às questões de gênero e de raça ou etnia, etc...

Some-se a isso outro grupo de políticas para além das esferas de Justiça que preveem a promoção de estudos e pesquisas, estatísticas e outras informações relevantes, com a perspectiva de gênero e de raça ou etnia, concernentes às causas, às consequências e à frequência da violência doméstica e familiar contra a mulher, para a 
sistematização de dados, a serem unificados nacionalmente, e a avaliação periódica dos resultados das medidas adotadas, a promoção de programas educacionais que disseminem valores éticos de irrestrito respeito à dignidade da pessoa humana com a perspectiva de gênero e de raça ou etnia e o destaque, nos currículos escolares de todos os níveis de ensino, para os conteúdos relativos aos direitos humanos, à equidade de gênero e de raça ou etnia e ao problema da violência doméstica e familiar contra a mulher.

Nos termos de promoção de estudos e pesquisas, estatísticas e outras informações relevantes, com a perspectiva de gênero e de raça ou etnia, pode-se listar a sequência de editais que, desde 2008, vêm sendo promovidos pela Secretaria de Políticas para as Mulheres (SPM) em parceria com o $\mathrm{CNPQ}^{25}$.

Dentre programas educacionais que podem ser destacados destaca-se o prêmio Construindo a Igualdade de Gênero ${ }^{26}$, concurso de redações, artigos científicos e projetos pedagógicos destinados a estudantes do ensino médio, graduação, graduados, mestrandos, mestres e doutorandos

\section{a5. Prevenção estrita}

Sobre a chamada prevenção estrita, é possível observar que, à semelhança do que ocorre no Informe de 2006 da Relatora Especial da ONU sobre a violência contra a mulher, suas causas e consequências a Lei n. ${ }^{\circ}$ 11.340/06 trouxe na parte policial uma série de procedimentos semelhantes enunciados nos artigos 10, 11 e 12 :

\footnotetext{
Art. 10. Na hipótese da iminência ou da prática de violência doméstica e familiar contra a mulher, a autoridade policial que tomar conhecimento da ocorrência adotará, de imediato, as providências legais cabíveis.

Parágrafo único. Aplica-se o disposto no caput deste artigo ao descumprimento de medida protetiva de urgência deferida.

Art. 11. No atendimento à mulher em situação de violência doméstica e familiar, a autoridade policial deverá, entre outras providências:

I - garantir proteção policial, quando necessário, comunicando de imediato ao Ministério Público e ao Poder Judiciário;

II - encaminhar a ofendida ao hospital ou posto de saúde e ao Instituto Médico Legal;

III - fornecer transporte para a ofendida e seus dependentes para abrigo ou local seguro, quando houver risco de vida;

IV - se necessário, acompanhar a ofendida para assegurar a retirada de seus pertences do local da ocorrência ou do domicílio familiar;
}

25 Uma amostra desses editais pode ser achada em http://www.spm.gov.br/sobre/editais

26 http://www.igualdadedegenero.cnpq.br/igualdade.html 
V - informar à ofendida os direitos a ela conferidos nesta Lei e os serviços disponíveis.

Art. 12. Em todos os casos de violência doméstica e familiar contra a mulher, feito o registro da ocorrência, deverá a autoridade policial adotar, de imediato, os seguintes procedimentos, sem prejuízo daqueles previstos no Código de Processo Penal:

I - ouvir a ofendida, lavrar o boletim de ocorrência e tomar a representação a termo, se apresentada;

II - colher todas as provas que servirem para o esclarecimento do fato e de suas circunstâncias;

III - remeter, no prazo de 48 (quarenta e oito) horas, expediente apartado ao juiz com o pedido da ofendida, para a concessão de medidas protetivas de urgência;

IV - determinar que se proceda ao exame de corpo de delito da ofendida e requisitar outros exames periciais necessários;

$\mathrm{V}$ - ouvir o agressor e as testemunhas;

VI - ordenar a identificação do agressor e fazer juntar aos autos sua folha de antecedentes criminais, indicando a existência de mandado de prisão ou registro de outras ocorrências policiais contra ele;

VII - remeter, no prazo legal, os autos do inquérito policial ao juiz e ao Ministério Público.

§ 1ํ O pedido da ofendida será tomado a termo pela autoridade policial e deverá conter:

I - qualificação da ofendida e do agressor;

II - nome e idade dos dependentes;

III - descrição sucinta do fato e das medidas protetivas solicitadas pela ofendida.

$\S 2^{\circ}$ A autoridade policial deverá anexar ao documento referido no

$\S$ 1o boletim de ocorrência e cópia de todos os documentos disponíveis em posse da ofendida.

$\S 3$ - Serão admitidos como meios de prova os laudos ou prontuários médicos fornecidos por hospitais e postos de saúde.

Da mesma forma, quando se trata da atuação do Judiciário, é importante ressaltar que o Direito brasileiro abraçou boa parte dos parâmetros previstos no ordenamento internacional com a consagração das chamadas medidas protetivas de urgência.

Talvez a grande inovação trazida pela Lei n. $^{\circ}$ 11.340/06 tenha sido a previsão, a semelhança do que faz a lei espanhola, das chamadas medidas protetivas de urgência, que são medidas de natureza cautelar destinadas a realização dos procedimentos inadiáveis na busca da tutela dos direitos da mulher vítima de violência (BATISTA, 2007, P. 8).

Essas são divididas em dois grupos: as medidas protetivas de urgência que obrigam o agressor (art. 22 da Lei n. ${ }^{\circ}$ 11.340/06) e as medidas protetivas de urgência à ofendida (art. 23 da Lei n. ${ }^{\circ}$ 11.340/06). 
No primeiro grupo podem ser listadas: suspensão da posse ou restrição do porte de armas, com comunicação ao órgão competente, nos termos da Lei $\mathrm{n}^{\circ} 10.826$, de 22 de dezembro de 2003, afastamento do lar, domicílio ou local de convivência com a ofendida, proibição de determinadas condutas, entre as quais aproximação da ofendida, de seus familiares e das testemunhas, fixando o limite mínimo de distância entre estes e o agressor, contato com a ofendida, seus familiares e testemunhas por qualquer meio de comunicação, frequentação de determinados lugares a fim de preservar a integridade física e psicológica da ofendida, restrição ou suspensão de visitas aos dependentes menores, ouvida a equipe de atendimento multidisciplinar ou serviço similar; e prestação de alimentos provisionais ou provisórios.

Já no segundo grupo pode-se enquadrar a possibilidade de o magistrado encaminhar a ofendida e seus dependentes a programa oficial ou comunitário de proteção ou de atendimento, determinar a recondução da ofendida e a de seus dependentes ao respectivo domicílio, após afastamento do agressor, determinar o afastamento da ofendida do lar, sem prejuízo dos direitos relativos a bens, guarda dos filhos e alimentos, determinar a separação de corpos. Também pode ser determinada a restituição de bens indevidamente subtraídos pelo agressor à ofendida, a proibição temporária para a celebração de atos e contratos de compra, venda e locação de propriedade em comum, salvo expressa autorização judicial, a suspensão das procurações conferidas pela ofendida ao agressor e a prestação de caução provisória, mediante depósito judicial, por perdas e danos materiais decorrentes da prática de violência doméstica e familiar contra a ofendida.

Desta forma, percebe-se que as medidas protetivas de urgência contêm normas basicamente de Direito Administrativo, Direito Civil e Direito de Família. Registre-se que além desses dispositivos, o juiz ainda pode determinar a inclusão da mulher em situação de violência doméstica e familiar no cadastro de programas assistenciais do governo federal, estadual e municipal, bem como assegurá-la o acesso prioritário à remoção quando servidora pública, integrante da administração direta ou indireta e a manutenção do vínculo trabalhista, quando necessário o afastamento do local de trabalho, por até seis meses, agregando-se dispositivos de natureza trabalhista, e previdenciária à hipótese ${ }^{27}$.

Perceba-se que essa multiplicidade de medidas pode ser utilizada por um mesmo e único magistrado que possui essa competência mista capaz de lançar mão de 27 Artigo $9^{\circ}, \S^{\circ}$ da Lei n. ${ }^{\circ} 11.340 / 06$. 
instrumentos dos mais variados com o objetivo de combater um fenômeno que é multicausal: a violência doméstica e familiar contra a mulher.

Nota-se assim que o conjunto representado pelas medidas ora listadas representa uma verdadeira rede de proteção constituída em favor da mulher vítima de violência, com o objetivo de livrá-la daquela situação de opressão.

\section{Conclusão:}

Percebe-se pelo exposto que o Direito brasileiro foi bastante permeável e receptivo aos parâmetro estabelecidos no Direito Internacional dos Direitos Humanos com relação à obrigação de prevenir a violência doméstica e familiar contra a mulher.

Talvez pela provocação internacional originária da Lei, vê-se que, com relação às formas de violência, o Direito brasileiro foi além das previsões ao listar como espécies de violência contra a mulher a violência física, a psicológica, a sexual, a patrimonial e a moral. Não bastasse isso, a desvinculação da orientação sexual para que a mulher seja passível de tutela pela Lei n. ${ }^{\circ}$ 11.340/06 parece ter sido também outro ponto positivo da legislação brasileira.

Quanto à obrigação geral de prevenir, verifica-se que as ações previstas pela legislação brasileira, a maioria delas efetivamente implementadas, aproximam-se daqueles parâmetros previstos pelo Direito Internacional dos Direitos Humanos.

A situação não é diferente quando se trata da obrigação de prevenção estrita, sendo certo que os padrões destinados à autoridade policial e ao Judiciário brasileiros estão em perfeita conformidade com os mandamentos internacionais. Assim, concluise que existe uma desejável harmonia entre os dispositivos de Direito interno no Brasil no tocante à obrigação de prevenção à violência doméstica e familiar contra a mulher e os parâmetros do Direito Internacional dos Direitos Humanos que tratam da mesma temática.

\section{Bibliografia:}

AMBOS, Kai. A parte geral do Direito Penal Internacional: bases para uma elaboração dogmática. São Paulo: RT, 2008.

Anistia Internacional \& Redress, Gender and Torture: Conference Report, Disponível

em

$<$ http://www.redress.org/downloads/publications/GenderandTortureConferenceReport

\section{-191011.pdf>}


Assembleia Geral da ONU, A/RES/48/104, 23 de fevereiro de 1994

Assembleia Geral da ONU, A/66/215, de 1 de agosto de 2011

BATISTA, Nilo. Só Carolina não viu. In: MELO, Adriana (Org.). Comentários à Lei de Violência Doméstica e Familiar Contra a Mulher. Rio de Janeiro: Lúmen Júris,2007.

BRASIL. Supremo Tribunal Federal. ADI 4424 e ADC 19. Disponível em http://www.stf.jus.br/portal/jurisprudencia/listarJurisprudencia.asp?s1=\%28ADI

$\% 29 \% 284424 \% 2 \mathrm{ENUME} \% 2 \mathrm{E}+\mathrm{OU}+4424 \% 2 \mathrm{EACMS} \% 2 \mathrm{E} \% 29 \&$ base=baseAcordaos\&url $=\mathrm{http}: / /$ tinyurl.com $/ \mathrm{m} 7 \mathrm{pdm} 6 \mathrm{~b}$

CAMPOS, Carmen Hein de. "Razão e Sensibilidade: teoria feminista do direito e Lei Maria da Penha". In CAMPOS, Carmen Hein de (Org). Lei Maria da Penha Comentada em uma perspectiva jurídico-feminista. Rio de Janeiro: Lumen Juris, 2011.

Comitê para Eliminação da Discriminação contra a Mulher , $11^{\text {th }}$ sessão, 1992

Convenção do Conselho da Europa para a Prevenção e Combate à Violência contra as Mulheres e à Violência Doméstica (2014)

Corte Europeia de Direitos Humanos. Opuz v. Turkey (9 de Junho 2009, §111)Corte Europeia de Direitos Humanos. Osman v. Reino Unido (1999) 29E.H.R.R.245 ECtHR, parágrafo 115

FEIX, Virgínia. "Das formas de violência contra a mulher - artigo $7^{o}$ ". In CAMPOS, Carmen Hein de (Org). Lei Maria da Penha Comentada em uma perspectiva jurídico-feminista. Rio de Janeiro: Lumen Juris, 2011.

MACKINNON, Catharine (1993), "On torture: A feminist perspective on human rights", in MAHONEY \& MAHONEY (ed) Human Rights in the Twenty-First Century: A Global Challenge. Dordrecht Neth: Martinus Nijhoff, 1993

MEYERSFELD, Bonita. Domestic Violence and International Law. Oxford: Hart Publishing, 2010

MEYERSFELD, Bonita. "Opuz v. Turkey: Confirming the State Obligation to Combat Domestic Violence. In European Human Rights Law Review. No.5, 2009.

NUCCI, 2007. Pag. 1.043 - NUCCI, Guilherme de Souza. Leis penais e processuais penais comentadas. 2. ed. São Paulo: Editora Revista dos Tribunais, 2007.

OEA. Comissão Interamericana de Direitos Humanos. Relatório 54/2001. 
OEA. Corte Interamericana de Direitos Humanos Caso González et. al. vs. México (Caso do Campo Algodoeiro). Julgamento 16 de Novembro de 2009

ONU Resolução 2003/45 da Comissão de Direitos Humanos

ONU Comitê CEDAW. Comunicações individuais n. 02/2003 (Ms. A.T. v. Hungria) e No. 05/2005 (Ms. Sahide Goecke v. Austria)

Mulher, 1995.

ONU. Declaração e Plataforma de ação da IV Conferência Mundial sobre a

SAFFIOTI, Heleieth I. B. Já se mete a colher em briga de marido e mulher. São Paulo em Perspectiva, Revista da Fundação SEADE, São Paulo, Vol. 13/No 4, p. $82-91$

SIMIONI, Fabiane e DA CRUZ, Rúbia Abs. "Da violência doméstica e familiar - artigo $5^{o}$ ". In CAMPOS, Carmen Hein de (Org). Lei Maria da Penha Comentada em uma perspectiva jurídico-feminista. Rio de Janeiro: Lumen Juris, 2011

Tribunal Internacional Penal para Ex-Iugoslávia (ICTY), Câmara de Apelação, Prosecutor v Kunarac et. al, 12 de junho de 2002 